\title{
Optimization of boron-doping process of titania nanotubes via electrochemical method toward enhanced photoactivity
}

\author{
Mariusz Szkoda $^{1}$ - Anna Lisowska-Oleksiak ${ }^{1}$ - Katarzyna Siuzdak ${ }^{2}$
}

Received: 7 January 2016 / Revised: 15 March 2016 / Accepted: 17 March 2016/Published online: 31 March 2016

(C) The Author(s) 2016. This article is published with open access at Springerlink.com

\begin{abstract}
In this work, we were focused on the development of the electrochemical approach resulting in a stable boron doping of titania nanotubes. The doping procedure concerns anodic polarization of as-anodized titania in a $\mathrm{H}_{3} \mathrm{BO}_{3}$ solution acting as $\mathrm{n}$ boron precursor. The series of attempts were taken in order to elaborate the most beneficial doping conditions. The parameters of electrochemical doping allowing to obtain boron-doped titania characterized by the highest photoconversion efficiency are as follows: reaction voltage $1.8 \mathrm{~V}$, process duration $0.5 \mathrm{~h}$, and the concentration of boric acid $0.5 \mathrm{M}$. Spectroscopy techniques such as UV-vis, X-ray diffraction, photoluminescence emission, and X-ray photoelectron spectroscopy were used to characterize the absorbance capability and the crystalline phase, to confirm the presence of boron atoms and to study the nature of chemical compounds, respectively. The well-ordered structure of titania and resistance of its morphology toward electrochemical treatment in $\mathrm{H}_{3} \mathrm{BO}_{3}$ were confirmed by scanning electron microscopy images. However, cyclic voltammetry and electrochemical impedance spectroscopy studies showed the significant difference in conductivity and capacitance between doped and pristine titania. Moreover, the photocurrent densities of the B-doped sample were about seven times higher in comparison with those generated by the pure titania nanotube electrode.
\end{abstract}

Mariusz Szkoda

mariusz-szkoda@wp.pl

1 Department of Chemistry and Technology of Functional Materials, Chemical Faculty, Gdańsk University of Technology, Narutowicza 11/12, 80-233 Gdańsk, Poland

2 Centre for Plasma and Laser Engineering, Szewalski Institute of Fluid Flow Machinery, Polish Academy of Science, Fiszera 14, 80-231 Gdańsk, Poland
Keywords $\mathrm{TiO}_{2}$ nanotubes $\cdot$ Boron doping $\cdot$ Anodization . Photocurrent $\cdot$ Electrochemical doping

\section{Introduction}

In the last decades, the development of photochemical systems capable of harnessing solar energy to produce electricity or chemical fuels has attracted significant interest $[1,2]$. The most of research strategies focus on novel types of semiconductors exhibiting photocatalytic activity [3]. In particular, titanium dioxide is regarded as a promising semiconducting material for photoelectrochemical applications due to its low cost, non-toxicity, and stability against photocorrosion [4-6]. However, the activity of titania nanotubes in processes carried out under illumination is limited by their wide bandgap $\left(E_{\mathrm{bg}}=3.2 \mathrm{eV}\right)$ that corresponds to energy provided by ultraviolet light $[7,8]$. For this reason, many approaches have been made to improve the activity of $\mathrm{TiO}_{2}$ that allows its efficient utilization under natural light source - sun. The vast majority of known strategies concerning material modification are based on metal [9-12] and non-metal doping [13-16], formation of organic-inorganic junctions [17], or surface sensitization by dye molecules [18]. To initiate the visible-light-driven activity of titania, doping with non-metal atoms (I, B, C, N, and $\mathrm{S}$ ) has been considered as a one of the most effective approaches that results in stable material with improved photoactivity compared to the unmodified sample $[19,20]$.

Recently, doping of $\mathrm{TiO}_{2}$ with boron has been widely studied in terms of its effect on the surface and the bulk structure which changes the ability of tailoring the bandgap, suppresses electron-hole pairs from recombination, and improves electron conductivity [21-23]. Some papers have reported that B-doped $\mathrm{TiO}_{2}$ powders obtained by a modified sol-gel method showed a red-shifted absorption spectrum [24, 25], while 
other studies concern increase in the bandgap energy of $\mathrm{TiO}_{2}$ upon doping when $\mathrm{H}_{3} \mathrm{BO}_{3}$ was used as a boron precursor because of the decrease of the crystal size after incorporation of boron atoms [21]. According to Bettinelli et al. [21], boron used as a titania dopant could favor the transformation of anatase to rutile. On the other hand, Finazzi et al. [26] reported that $\mathrm{B}$ atoms in the anatase crystal could occupy different positions and promote changes in the electronic structure of boron-doped $\mathrm{TiO}_{2}$ that is in accordance to the results of density functional theory. In general, previous results on borondoped titania nanoparticles suggest that preparation method highly impacts on material properties, but simultaneous decrease of bandgap energy value is not always observed.

In this work, we present a new boron doping of titania nanotube $\left(\mathrm{TiO}_{2} \mathrm{NT}\right)$ approach realized during an electrochemical process carried out at constant voltage when as-anodized titanium plate is immersed in electrolyte containing boric acid as a boron precursor. This method could be regarded as a simple, cheap, and fast doping procedure that enables control of the photoactivity of obtained material. The series of attempts were undertaken in order to optimize the electrochemical doping conditions. The concentration of boric acid and process duration were the main factors that influenced the boron-doping effect on the registered photocurrent. Differences between pure and doped titania were emphasized using various spectroscopic techniques: UV-vis, X-ray diffraction, Fourier transformed infrared, photoluminescence emission spectroscopy, and X-ray photoelectron spectroscopy. The optimal experimental parameters based on the exhibited photocurrent density were determined. Furthermore, performed cyclic voltammetry and impedance spectroscopy measurements were used to characterize electrochemical activity of the most photoactive boron-doped titania.

\section{Experimental}

\section{Material preparation}

The substrate sample (Ti plate, Strem, $99.7 \%$ ) was ultrasonically cleaned in the following order: in acetone, ethanol, and water for $10 \mathrm{~min}$ in each solvent and finally dried in the air. Titania nanotubes were prepared via a two-step electrochemical anodization of Ti plate in solution containing fluoride ions that leads to formation of highly ordered tubular structure $[10$, 27]. The process was realized in a two-electrode configuration, where the titanium metal foil served as an anode and the platinum mesh as a cathode placed at a fixed separation of $2 \mathrm{~cm}$. The first anodization took place in the electrolyte containing the following: ethylene glycol (EG), $0.27 \mathrm{M} \mathrm{NH}_{4} \mathrm{~F}$, and $1 \mathrm{vol} \%$ of deionized water. Anodization was performed at $40 \mathrm{~V}$ for $2 \mathrm{~h}$, with the initial voltage rate of $0.1 \mathrm{~V} / \mathrm{s}$. Then, the titanium plate was immersed for $12 \mathrm{~h}$ in $0.5 \% \mathrm{wt}$. solution of oxalic acid in order to remove the first rugged nanotube layer. The second anodization was performed on the ascleaned titanium plate under the same conditions as during the first anodization. In order to remove any surface debris, the titanium plates covered with nanotubes were put into diluted HF $(0.05 \%)$ solution for $180 \mathrm{~s}$.

As-anodized titania plates were used for further electrochemical doping. It was realized in a two-electrode arrangement, during which the previously prepared titania nanotubes served as an anode and the Pt mesh plate as a cathode immersed in solution of boric acid. The optimization of the electrochemical doping [28] approach was realized in different conditions: reaction times: 15,30 , and $60 \mathrm{~min}$ and $\mathrm{H}_{3} \mathrm{BO}_{3}$ concentrations: $0.1,0.5$, and $1 \mathrm{M}$. The doping process was performed under $1.8-\mathrm{V}$ voltage between electrodes. Finally, the samples (pure and doped $\mathrm{TiO}_{2} \mathrm{NTs}$ ) were rinsed with deionized water, dried in the air, and thermally treated at $450{ }^{\circ} \mathrm{C}$ for $2 \mathrm{~h}$ with a heating rate of $2{ }^{\circ} \mathrm{C} \mathrm{min}{ }^{-1}$ to transform the amorphous $\mathrm{TiO}_{2}$ into a crystalline phase.

\section{Characterization}

The sample morphology (top-view and cross-sectional) was investigated by Schottky field emission scanning electron microscopy (FEI Quanta FEG 250) with ET secondary electron detector. The crystalline phase of obtained materials was identified by X-ray diffraction (XRD, Rigaku Miniflex 600) analysis. The measurements were performed with $\mathrm{Cu} \mathrm{K} \alpha$ radiation at $2 \theta$ angles from $5^{\circ}$ to $90^{\circ}$ with scan speed of $0.02^{\circ} \mathrm{min}^{-1}$. Crystallite size was calculated from the half height width of the (101) diffraction peak of anatase using the Scherrer equation. The reflectance spectra of titania nanotubes were measured with a dual-beam UV-vis spectrophotometer (Lambda 35 , PerkinElmer) equipped with a diffuse reflectance accessory. Bandgap energy values were determined as the intercept of the tangent of the plot of transformation of the Kubelka-Munk function $\left(\mathrm{KM}^{0.5} E_{\mathrm{ph}}{ }^{0.5}\right)$ vs. photon energy. The Fourier transform infrared spectroscopy (FTIR) measurements were performed using a Nicolet iS50 spectrometer equipped with the Specac Quest single-reflection diamond attenuated total reflectance (ATR) accessory. Spectral analysis was controlled by the OMNIC software package. The FTIR spectra were recorded in the range of $400-4000 \mathrm{~cm}^{-1}$. The photoluminescence spectroscopy (PL) measurements were carried out using laboratory setup consisting of $0.3 \mathrm{~m}$ Czerny-Turner spectrograph (SR303i, Andor) equipped with an ICCD camera (DH740, Andor). Samples of pure and boron-doped $\mathrm{TiO}_{2}$ were excited with UV LED (center wavelength $365 \mathrm{~nm}$, FWHM $9 \mathrm{~nm}$, output power $350 \mathrm{~mW}$ ). PL experiments were carried out in order to determine the quenching efficiency of charge carrier in semiconductor. Escalab 250Xi by Thermo Fisher Scientific was used to perform high-resolution X-ray photoelectron spectroscopy (XPS) 
measurements to determine the chemical binding properties of the surface, utilizing monochromatic $\mathrm{Al} \mathrm{K} \alpha$ source with charge neutralization implemented by means of a flood gun. High-resolution spectra were recorded at energy step size of $0.1 \mathrm{eV}$ at pass energy of $10 \mathrm{eV}$. In order to normalize spectroscopic measurements, $X$-axis (binding energy, $E_{\mathrm{bin}}$ ) from XPS spectrum was calibrated for peak characteristics of neutral carbon $1 \mathrm{~s}\left(E_{\mathrm{bin}}=284.6 \mathrm{eV}\right)$. Data analysis was performed using the Avantage software provided by the manufacturer.

\section{Electrochemical characterization}

Electrochemical experiments (cyclic voltammetry (CV) and electrochemical impedance spectroscopy (EIS)) were performed using an Autolab PGStat $302 \mathrm{~N}$ potentionstatgalvanostat system (Methrom, Autolab) in the standard three-electrode arrangement, where titanium foil covered with $6+$ nanotubes served as a working electrode (geometric surface area of $\left.0.5 \mathrm{~cm}^{2}\right), \mathrm{Ag} / \mathrm{AgCl} / 0.1 \mathrm{M} \mathrm{KCl}$ was used as a reference electrode, and platinum mesh acted as a counter electrode. Electrodes were tested in the contact with $0.5-\mathrm{M}$ $\mathrm{K}_{2} \mathrm{SO}_{4}$ solution at $23{ }^{\circ} \mathrm{C}$. $\mathrm{CV}$ was performed to characterize materials in contact with the deaerated aqueous electrolyte $(\mathrm{pH}=7)$. EIS measurements were conducted at the frequency range from $20 \mathrm{kHz}$ to $0.1 \mathrm{~Hz}$, covering 75 points and with 10$\mathrm{mV}$ amplitude of the AC signal. In order to perform the MottSchottky analysis, impedance spectra were recorded at different potentials in the range from +0.6 to $-0.5 \mathrm{~V}$ vs. $\mathrm{Ag} / \mathrm{AgCl} /$ $0.1 \mathrm{M} \mathrm{KCl}$. Before each spectra registration, the potential was held for $60 \mathrm{~s}$ to achieve a steady-state condition.

\section{Photoactivity characterization}

Measurements carried out under illumination were performed in the photoelectrochemical cell equipped with a quartz window and the cooling jacket keeping constant temperature at $23{ }^{\circ} \mathrm{C}\left( \pm 1^{\circ} \mathrm{C}\right)$ provided by thermostat (Julabo F-12) control. A high-pressure 150-W xenon lamp (Osram XBO 150) equipped with AM1.5 filter was used as a light source. The light intensity was adjusted to $100 \mathrm{~mW} \mathrm{~cm}^{-2}$ (controlled by power meter, Ophir).

\section{Results and discussion}

\section{Morphology and structure studies}

In Fig. 1, the top-view and cross-sectional images of pure and boron-doped titania nanotubes are presented. Since the morphologies for the entire set of B-doped $\mathrm{TiO}_{2}$ NTs arrays prepared in different conditions do not change significantly, the representative sample obtained under $1.8 \mathrm{~V}$, for $30 \mathrm{~min}$ and in $0.5-\mathrm{M}$ concentrated $\mathrm{H}_{3} \mathrm{BO}_{3}$ solution, is shown. The homogeneous layers are composed of highly ordered and aligned nanotubes. When comparing Fig. 1a, b SEM images, any noticeable difference was observed in the architecture between the doped and undoped materials. It suggests that electrochemical doping realized in boric acid solution did not cause any changes in the morphology of the $\mathrm{TiO}_{2}$ NT sample. The layer thickness was determined on the basis of a cross-sectional image. For pure and doped material, the length of nanotubes equals $2.5 \mu \mathrm{m}$. The nanotubes were characterized by an average internal diameter of $100 \mathrm{~nm}$ and a wall thickness of $25 \mathrm{~nm}$.

According to a geometric model [29] that considers a regular network of identical and equally spaced nanotubes, the real surface area of the layer composed of nanotube titania was estimated using the following equation:

$S_{t}=\frac{8 \pi \mathrm{h} R_{2}}{\sqrt{3}\left(4 R_{2}-2 R_{1}+y\right)^{2}} \cdot S_{\text {geo }}$

where $R_{1}$ and $R_{2}$, respectively, are the internal radium and the sum of $R_{1}$ and half thickness of the wall of the nanotubes, $y$ is the thickness of the slit between the tubes, $h$ is the average length of nanotube, and $S_{\text {geo }}$ states for a geometric surface area. Because the distance between each tube is almost imperceptible, the dimension of $y$ was not taken into account for calculations. As the value of the geometric surface, $1 \mathrm{~cm}^{2}$ was used for simplicity. Based on Eq. (1), the real surface area of the layer composed of nanotubes was estimated to be $120 \mathrm{~cm}^{2}$ both for pure and doped materials. Knowing that any difference in tube dimensions and overall real surface area between pristine and modified titania is not observed, only the presence of dopant atoms can have an impact on their structural properties and photoactivity [30,31].

The plot of Kubelka-Munk function vs. photon energy and the absorbance curves are presented in Fig. 2 and Fig. 2 inset, respectively. It can be clearly observed that the absorption edge position of B-doped $\mathrm{TiO}_{2}$ moves toward longer wavelengths. It is confirmed that electrochemical doping results in $\mathrm{TiO}_{2}$ with the obvious red shifted photoactivity and results in the bandgap narrowing [32]. The values of $E_{\mathrm{bg}}$ determined on the basis of the Tauc plot are 2.91 and $3.09 \mathrm{eV}$ for B-doped and pure $\mathrm{TiO}_{2}$ NTs, respectively. Among other non-metals used as titania dopands, boron atoms can be introduced into the $\mathrm{TiO}_{2}$ lattice and the $p$ orbital of $\mathrm{B}$ is mixed with $\mathrm{O} 2 p$ orbitals, leading to a shift in the optical response to the visible range [33]. This is due to the fact that the ion radius of $\mathrm{B}(\mathrm{III})$ $(0.023 \mathrm{~nm})$ is much smaller than that of Ti(IV) $(0.064 \mathrm{~nm})$. Therefore, boron oxides existing at the surface of the material can easily incorporate into the crystalline framework of titania [21, 34].

Figure 3a shows XRD spectra registered for boron-doped and pure titania layer. All detected crystallite phases were indexed as characteristic peaks of anatase (A) (JCPDS No. 21-1272) and the titanium (Ti) phase (JCPDS No. 44-1294) 

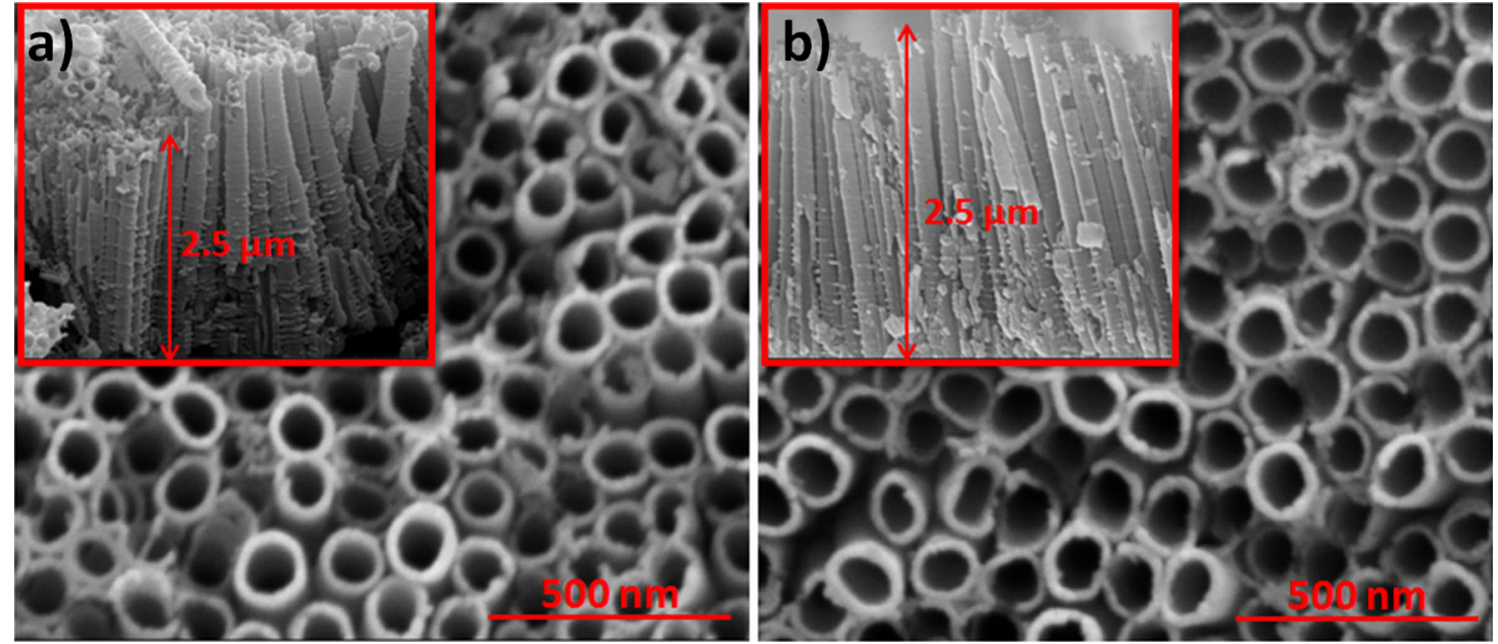

Fig. 1 Top-view and cross-sectional SEM image of a pure and $\mathbf{b}$ B-TiO ${ }_{2}$ NTs. The doping conditions are as follows: reaction voltage $1.8 \mathrm{~V}$, reaction time $0.5 \mathrm{~h}$, and electrolyte concentration $0.5 \mathrm{M}$

[21] acting as $\mathrm{TiO}_{2} \mathrm{NT}$ support. It should be noted that any peak typical for rutile was not observed. Furthermore, the lack of signal attributed to dopant atoms could result from their low content in the $\mathrm{B}-\mathrm{TiO}_{2}$ material and cannot be detected by XRD [35]. However, as it is shown in Fig. 3b, the addition of $\mathrm{B}$ atoms leads to changes in shape of $\mathrm{A}(101)$ peak. The increase of its intensity is related to the crystallinity improvement. According to Li et al. [22], such phenomena observed for B-doped $\mathrm{TiO}_{2}$ was due to the reduction of the grain boundaries and amorphous regions acting as charge carrier recombination centers. Basing on the Scherrer equation, crystallite size was calculated and equals $17.3 \mathrm{~nm}$ for pure and $20.4 \mathrm{~nm}$ for boron-doped titania. The increase of crystallite size can be ascribed to the incorporation of dopant atoms into the structure, e.g., substitution of the lattice oxygen/titanium atoms or introduction of boron at the interstitial sites [36].

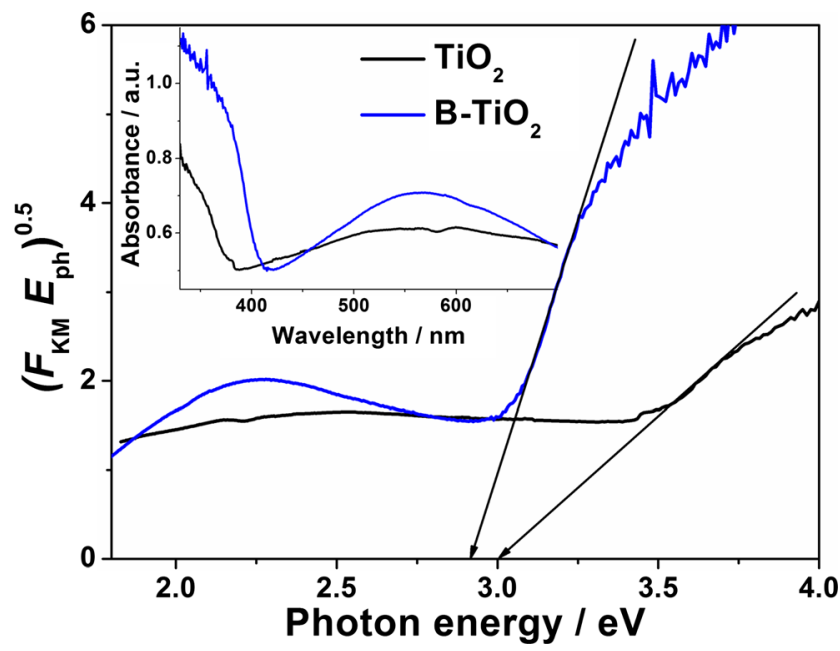

Fig. 2 The absorbance spectra and the Kubelka-Munk function for pure and B-doped titania. The doping conditions are as follows: reaction voltage $1.8 \mathrm{~V}$, reaction time $0.5 \mathrm{~h}$, and electrolyte concentration $0.5 \mathrm{M}$
Figure 4 shows FTIR spectra of pure and $\mathrm{B}-\mathrm{TiO}_{2}$ samples. Both titania samples exhibit the main band between 400 and $700 \mathrm{~cm}^{-1}$, which are attributed to Ti-O stretching and Ti-OTi bridging stretching modes [37]. The peak found around $1000 \mathrm{~cm}^{-1}$ could be assigned to the stretching vibration of $\mathrm{Ti}-\mathrm{O}$ and $\mathrm{Ti}-\mathrm{O}-\mathrm{Ti}$ [22]. The bands observed at about 3400 and $1600 \mathrm{~cm}^{-1}$ are assigned to the stretching of hydroxyl groups and the bending vibration of water molecules adsorbed on the material surface [38]. In the case of $\mathrm{B}_{-} \mathrm{TiO}_{2}$ sample, the intensity of the FTIR spectra is higher than that of pristine titania. It is related to higher surface energy and larger amount of hydroxyl groups at the B-doped comparing to pristine titania [31].

The presence of boron and its chemical nature in $\mathrm{TiO}_{2} \mathrm{NTs}$ layers were studied using the XPS. The high-resolution XPS spectra of the boron region were registered only in the case of doped titania. The XPS spectra obtained for pure and borondoped $\mathrm{TiO}_{2}$ were shown and discussed in our previous article [39]. According to these results, signals attributed to titanium, oxygen, and carbon were found in both $\mathrm{TiO}_{2} \mathrm{NT}$ samples. The positions of maxima of fitted spectra obtained for investigated materials are listed in Table 1. The XPS spectrum of B1s region registered at the titania surface exhibits two singlet peaks. One of them with the binding energy of $190.71 \mathrm{eV}$ is assigned to boron directly linked to titanium atoms [40], whereas the second signal with maximum found at $192.64 \mathrm{eV}$ results from presence of Ti-O-B or B-O-B arrangement [41]. According to literature [27], boron atoms could occupy interstitial sites in anatase crystals and thereby take part in the balance of residual charge. Such location of boron ions is justified by almost three times smaller radius of B(III) comparing to Ti(IV) [17]. Taking into account only oxygen linked to boron and titanium, the atomic ratio of $\mathrm{Ti} /$ O/B found at the material surface equals: 1:2.39:0.73. However, XPS investigation performed after subsequent 

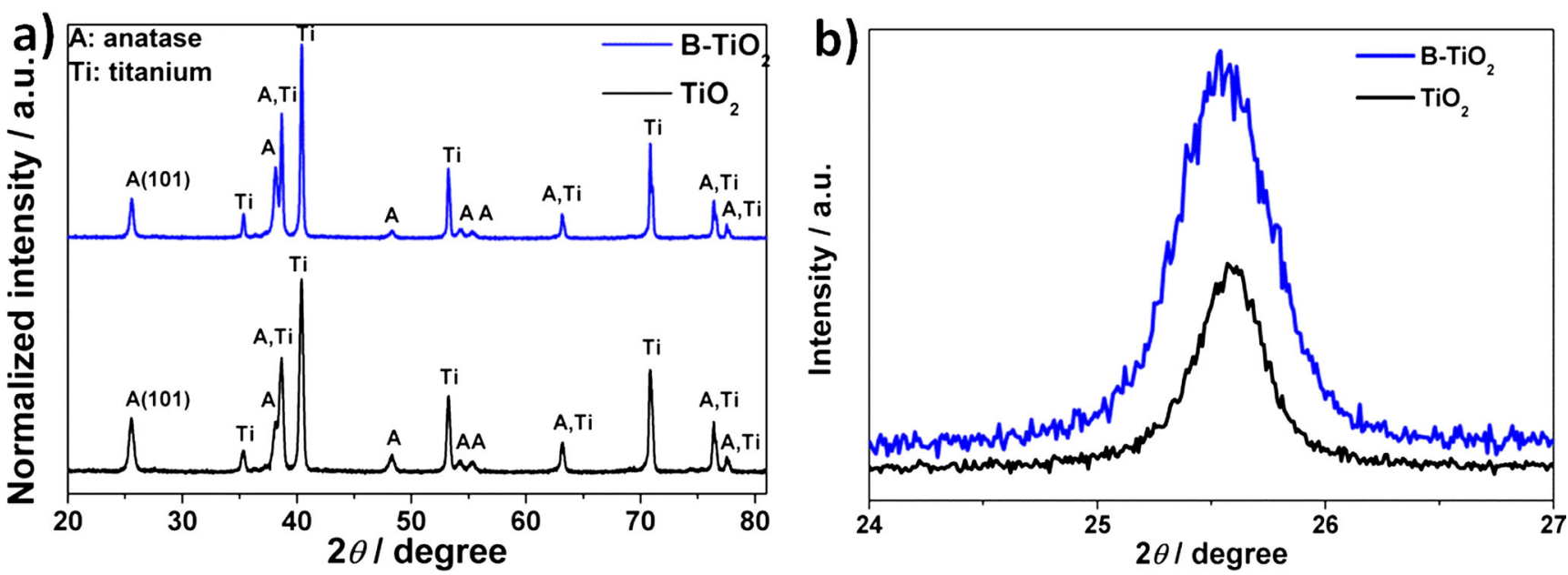

Fig. 3 a XRD patterns of pure and boron-doped titania and $\mathbf{b}$ the magnification of $\mathrm{A}(101)$ peak extracted from XRD patterns. The doping conditions are as follows: reaction voltage $1.8 \mathrm{~V}$, reaction time $0.5 \mathrm{~h}$, and electrolyte concentration $0.5 \mathrm{M}$.

etching of titania layer shows decrease in boron content down to $2.74 \%$ and the signal attributed to the $\mathrm{B}-\mathrm{O}$ arrangement disappears (see Fig. 5). The difference in boron distribution at the external layer and inside the material could result from adsorption of boric acid on the titania surface in a form of monodentate arrangement: $-\mathrm{HOB}(\mathrm{OH}) \mathrm{O}(\mathrm{H})-\mathrm{Ti}[42]$. Therefore, because of significant amount of surface boron species, the increase in hydroxyl groups amount observed on FTIR spectra comparing to pristine titania provides the neutrality of $\mathrm{B}-\mathrm{TiO}_{2}$ surface [43].

In the case of XPS spectra registered for titanium and oxygen, the shift in binding energy value both for Ti2 $p$ and $\mathrm{O} 1 s$ is observed. That may be caused by the introduction of boron ions into the titania lattice. Furthermore, in the case of $\mathrm{B}-\mathrm{TiO}_{2}$, additional oxygen signal was found that is related to the oxygen linked to boron.

The photoluminescence spectra (PL) of undoped and boron-doped samples excited at a wavelength of $365 \mathrm{~nm}$ at room temperature are presented in Fig. 6. PL is commonly used for examination of the rate of recombination, the electronic structure of nanomaterials, and the transfer behavior of the photoexcited electron-hole pairs in semiconductors. The

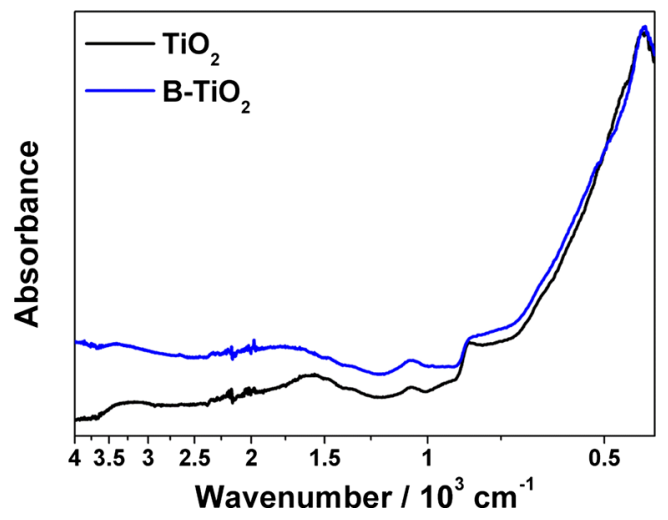

Fig. 4 FTIR spectra of pure and boron-doped $\mathrm{TiO}_{2}$ nanotubes luminescence intensity is strongly related with the radiative recombination of photogenerated electrons and holes, so the higher the intensity of PL, the greater the likelihood of occurrence of electron-hole recombination processes [44]. For both materials, the registered PL spectra are characterized by a broad band in the range of 480-600 $\mathrm{nm}$ with a maximum at $530 \mathrm{~nm}$ that is attributed to activity of surface states [45]. The doped titania nanotubes exhibit lower intensity of photoluminescence than pure $\mathrm{TiO}_{2}$. Thus, it can be expected that boron atoms efficiently participate in a charge carrier separation and significantly inhibit radiative recombination processes [46]. Furthermore, according to Begum et al. [47], boron atoms can be located in the interstitial positions of the $\mathrm{TiO}_{2}$ lattice leading to the partial reduction of $\mathrm{Ti}(\mathrm{IV})$ to Ti(III), which could act as an electron trap.

\section{Electrochemical properties}

To evaluate the electrochemical properties of the obtained samples, $\mathrm{CV}$ and electrochemical impedance spectra were registered in $0.5 \mathrm{M} \mathrm{K}_{2} \mathrm{SO}_{4}$. In Fig. 7, typical CV curves of the B$\mathrm{TiO}_{2}$ and $\mathrm{TiO}_{2}$ electrodes collected at the scan rate of $20 \mathrm{mV} \mathrm{s}^{-1}$ were shown. As it could be seen, the area limited

Table 1 The position of species present in the doped and pure $\mathrm{TiO}_{2}$ NTs

\begin{tabular}{llllll}
\hline Element & Boron & Titanium & & Oxygen & Carbon \\
\hline Core level & $\mathrm{B} 1 s(\mathrm{eV})$ & $\mathrm{Ti} 2 p_{1 / 2}(\mathrm{eV})$ & $\mathrm{Ti} 2 p_{3 / 2}(\mathrm{eV})$ & $\mathrm{O} 1 s(\mathrm{eV})$ & $\mathrm{C} 1 s(\mathrm{eV})$ \\
$\mathrm{TiO}_{2}$ & - & 458.80 & 464.40 & 529.20 & 284.70 \\
& & & & 531.70 & 286.00 \\
& & & & & 288.70 \\
${\mathrm{~B}-\mathrm{TiO}_{2}}^{190.71}$ & 458.99 & 464.75 & 530.18 & 284.78 \\
& 192.64 & & & 531.57 & 286.45 \\
& & & & 533.00 & 288.71 \\
\hline
\end{tabular}




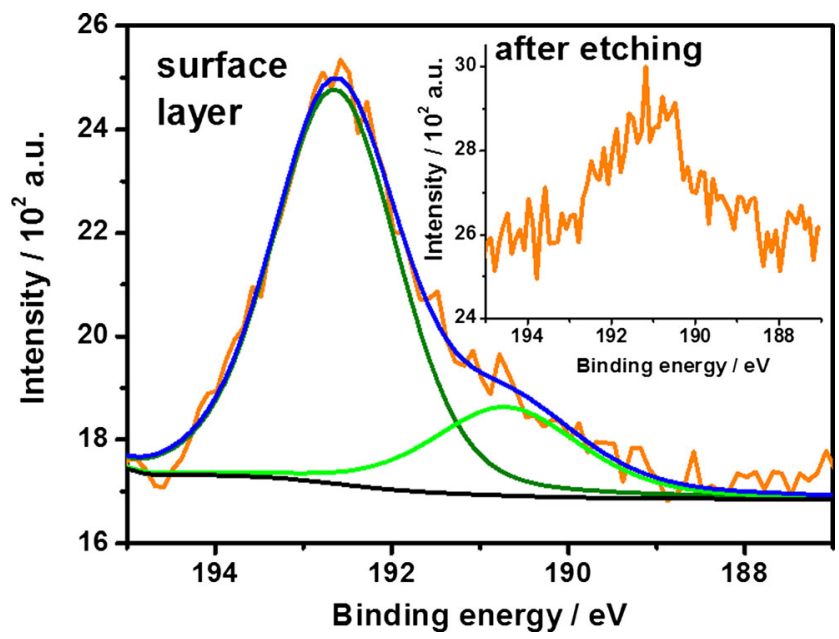

Fig. 5 High-resolution XPS spectra recorded at the boron region for B$\mathrm{TiO}_{2}$ sample

by the CV curve for boron-doped titania is much higher than that for pure material, which indicates higher electrical double-layer capacitance of $\mathrm{B}-\mathrm{TiO}_{2}$ comparing to undoped titania. Similar relations between double-layer capacitance of boron-containing and boron-free titania nanotubes were reported by $\mathrm{Li}$ et al. and were attributed to the presence of Ti(III) traces leading to increase of material conductivity [48].

Apart from higher capacitive current, on the reverse scan of $\mathrm{CV}$ registered for $\mathrm{B}-\mathrm{TiO}_{2}$, at about $-0.24 \mathrm{~V}$ vs. $\mathrm{Ag} / \mathrm{AgCl} /$ $0.1 \mathrm{M} \mathrm{KCl}$, additional cathodic peak arised (see B inset). As it was reported for other non-metal-doped titania nanotubes, it could be attributed to the reduction of Ti(IV) sites in $\mathrm{TiO}_{2}$ that causes change in the electronic structure of titania. It is related to the formation of additional energy levels within the bandgap, and as the result, both electrical conductivity and optical properties of material are different than that of pristine $\mathrm{TiO}_{2}$. Further cathodic polarization of electrode leads to initiation of the hydrogen evolution process. Additionally, the difference in $\mathrm{CV}$ run between boron-doped and pristine titania is observed in anodic potential range. In the case of $\mathrm{B}-\mathrm{TiO}_{2}$, the current increases more steeply comparing to unmodified

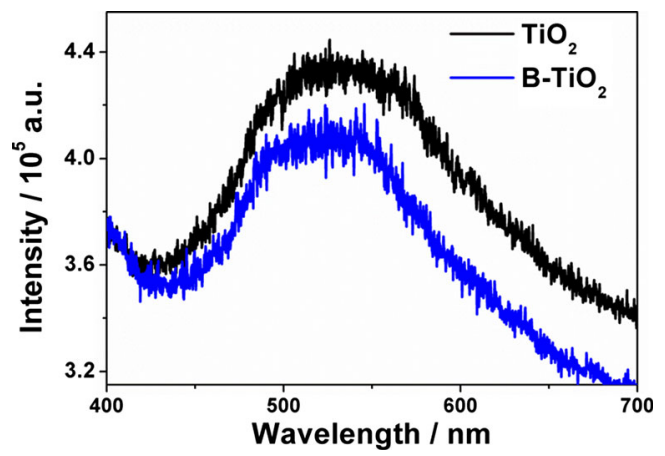

Fig. 6 Photoluminescence spectra of pure and B-doped sample. The doping conditions are as follows: reaction voltage is $1.8 \mathrm{~V}$, reaction time is $0.5 \mathrm{~h}$, and electrolyte concentration is $0.5 \mathrm{M}$

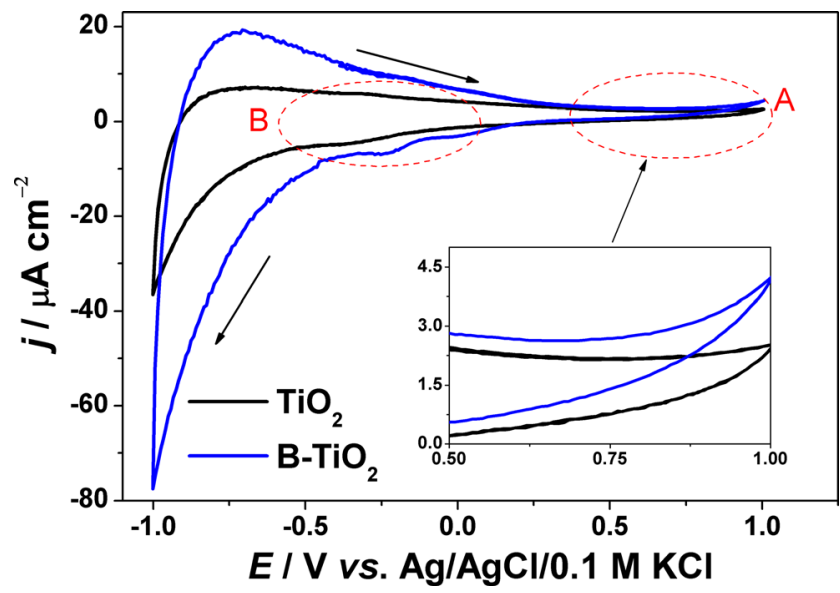

Fig. 7 Cyclic voltammetry curves recorded for doped and pure $\mathrm{TiO}_{2}$ immersed in $0.5 \mathrm{M} \mathrm{K}_{2} \mathrm{SO}_{4}, v=50 \mathrm{mV} \mathrm{s}^{-1}$

sample, showing that also anodic oxygen evolution reaction is facilitated upon boron doping [49].

EIS measurements were conducted on pure and borondoped titania in the wide potential range. In accordance to proposed approach for interpretation of EIS spectra registered for $\mathrm{TiO}_{2}$ nanotube arrays [8], Mott-Schottky analysis was performed. Thus, the plot shown in Fig. 8 was prepared on the basis of relation given as follows:

$\frac{1}{C^{2}}=\left(\frac{2}{q \varepsilon \varepsilon_{0} N_{\mathrm{D}}}\right)\left(E-E_{\mathrm{fb}}-\frac{k T}{q}\right)$

where $C$ is the areal capacity of the space charge layer, $q$-elementary charge, $\varepsilon_{0}$-vacuum permittivity, $\varepsilon$-dielectric constant, $N_{\mathrm{D}}$ concentration of donors, $E$-applied potential bias, $E_{\mathrm{fb}}$-flatband potential, $k$-Boltzmann's constant, and $T$-absolute temperature. The non-linear relation in the range from +0.8 to $-0.5 \mathrm{~V}$ vs. Ag/ $\mathrm{AgCl} / 0.1 \mathrm{M} \mathrm{KCl}$ is due to intrinsic electronic state [50] and

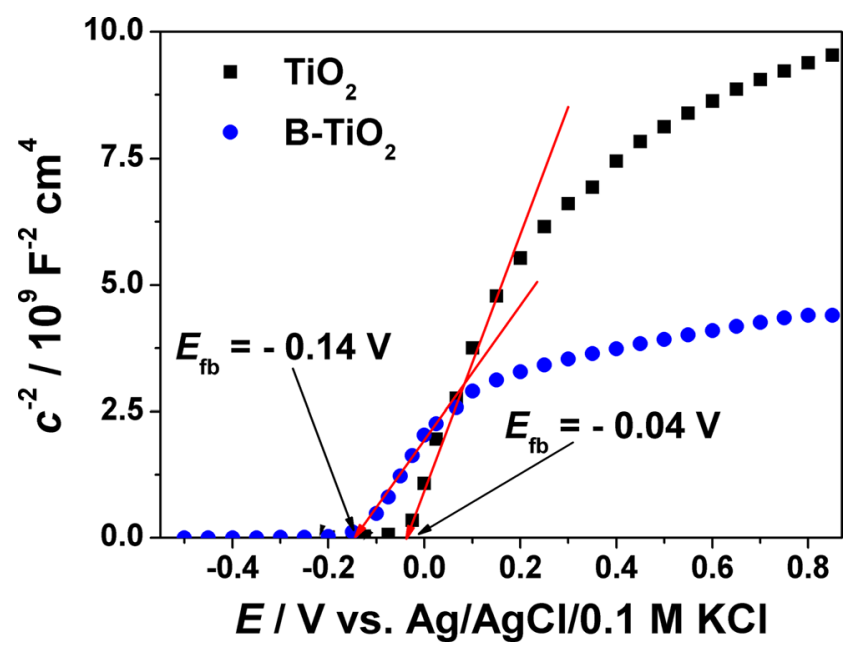

Fig. 8 The Mott-Schottky plot for pristine and boron-doped titania nanotubes 


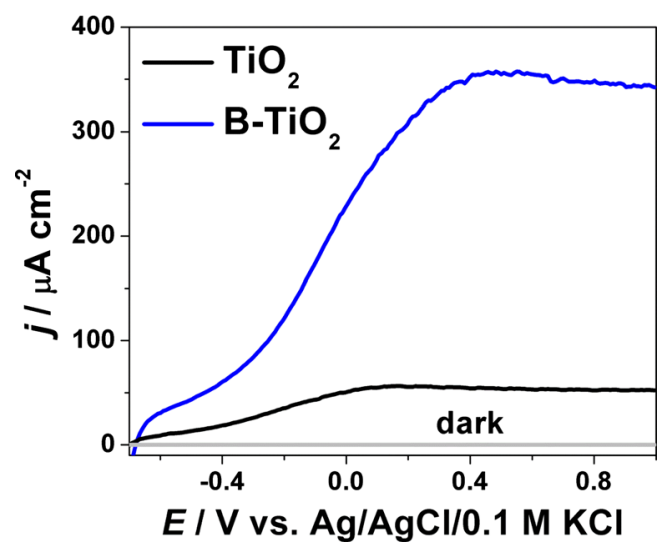

Fig. 9 Variation of photocurrent density under UV-vis illumination versus potential for pure and boron-doped titania in $0.5 \mathrm{M} \mathrm{K}_{2} \mathrm{SO}_{4}$ $\left(v=20 \mathrm{mV} \mathrm{s}^{-1}\right)$

could result from charging of bulk or surface states [51] or irregular inhomogeneous distribution of $\mathrm{O}^{2-}$ ions [52]. Both doped and pristine titania exhibit positive slope that is characteristic for n-type semiconductor, and from the intercept with $E$-axis, flatband potential could be determined [53]. For pure titania, $E_{\mathrm{fb}}$ equals $-0.04 \mathrm{~V}$ vs. $\mathrm{Ag} / \mathrm{AgCl} / 0.1 \mathrm{M} \mathrm{KCl}$, whereas in the case of $\mathrm{B}-\mathrm{TiO}_{2}, E_{\mathrm{fb}}$ value is anodically shifted to $-0.14 \mathrm{~V}$ vs. $\mathrm{Ag} / \mathrm{AgCl} / 0.1 \mathrm{M} \mathrm{KCl}$. Negative shift in $E_{\mathrm{fb}}$ can be attributed to the improved electron concentration and trap distribution [54] caused by boron doping.

Assuming that difference between $E_{\mathrm{fb}}$ and the bottom of the conduction band $(\mathrm{CB})$ is negligible, the position of $\mathrm{CB}$ could be identified with flatband potential value [13]. Knowing that bandgap energy for $\mathrm{B}^{-\mathrm{TiO}_{2}}$ equals $2.91 \mathrm{~V}$, the position of valence band (VB) according to the relation $E_{\mathrm{CB}}+$ $E_{\mathrm{bg}} \approx E_{\mathrm{VB}}$ could be estimated to be $2.77 \mathrm{~V}$ vs. $\mathrm{Ag} / \mathrm{AgCl} / 0.1 \mathrm{M}$ $\mathrm{KCl}$, whereas for pure titania, $E_{\mathrm{VB}} \approx 3.05 \mathrm{~V}$ vs. $\mathrm{Ag} / \mathrm{AgCl} /$ $0.1 \mathrm{M} \mathrm{KCl}$. Thus, anodic shift of the $\mathrm{CB}$ in the case of B$\mathrm{TiO}_{2}$ is accompanied by an anodic shift of the VB edge. This should improve the oxidation potential of the holes generated upon sample illumination [55].

Apart from change in $E_{\mathrm{fb}}$ position, the difference in slopes in Mott-Schottky plots is observed and indicates a disparity of
Table 2 The set of procedure parameters and photocurrent density values registered for each sample

\begin{tabular}{lllll}
\hline Assignment & $c\left(\mathrm{H}_{3} \mathrm{BO}_{3}\right)(\mathrm{M})$ & $t(\mathrm{~min})$ & $\left.j(\mu \mathrm{A} \mathrm{cm})^{-2}\right)$ & $\mathrm{EF}$ \\
\hline $\mathrm{A}$ & 0.1 & 15 & 119.7 & 2.87 \\
$\mathrm{~B}$ & 0.5 & 15 & 199.3 & 4.8 \\
$\mathrm{C}$ & 1 & 15 & 123.3 & 2.96 \\
$\mathrm{D}$ & 0.5 & 15 & 199.3 & 4.8 \\
E & 0.5 & 30 & 310.7 & 7.5 \\
$\mathrm{~F}$ & 0.5 & 60 & 232.8 & 5.6 \\
Pure $\mathrm{TiO}_{2}$ & - & - & 41.7 & - \\
\hline
\end{tabular}

donor densities in pure and boron-doped titania. The carrier density $N_{\mathrm{D}}$ could be calculated from the following equation:

$N \mathrm{D}=\left(2 / e \varepsilon \varepsilon_{0}\right)\left[\frac{d C^{-2}}{d E}\right]^{-1}$

when the following values are taken into account: $e=1.6 \times 10^{-19}, \varepsilon_{0}=8.86 \times 10^{-14} \mathrm{~F} / \mathrm{cm}$, and $\varepsilon=31$ for anatase [56]. The calculated donor densities of $\mathrm{TiO}_{2} \mathrm{NTs}$ and $\mathrm{B}-\mathrm{TiO}_{2}$ NTs equal to $1.98 \times 10^{20}$ and $1.82 \times 10^{21} \mathrm{~cm}^{-3}$, respectively. Despite the fact that the Mott-Schottky plot does not allow to estimate the absolute value of $N_{\mathrm{D}}$ [57], it is shown that upon electrochemical doping, donor density is ten times higher comparing to the unmodified sample. Such change was observed for other modified titania samples and is commonly attributed to the introduction of substantial oxygen vacancies that are regarded as electron donors in titania $[58,59]$ and implied faster carrier transfer in doped $\mathrm{TiO}_{2}$ comparing to pure titania [60].

\section{Photoelectroactivity}

The photocurrent densities as a function of potential of undoped and $\mathrm{B}$-doped $\mathrm{TiO}_{2}$ nanotube (exhibiting the highest photocurrent) electrodes exposed to radiation from a solar simulator equipped with an AM1.5 filter are presented in Fig. 9. The dark current is very low and can be negligible;
Fig. 10 Photocurrent response of pure titania and boron-doped nanotube array samples (A-F)
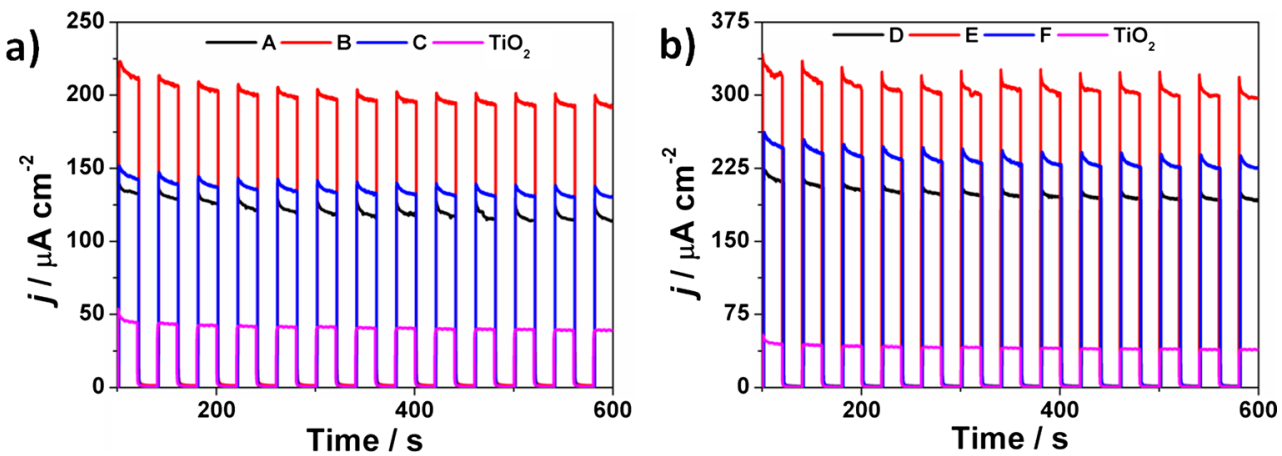


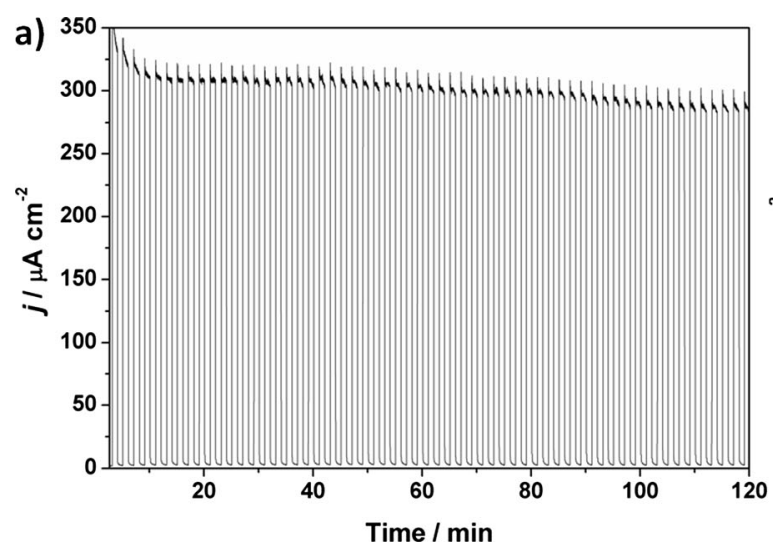

Fig. 11 a The long-term chronoamperometry test $(E=0.5 \mathrm{~V}$ vs. $\mathrm{Ag} /$ $\mathrm{AgCl}(0.1 \mathrm{M} \mathrm{KCl}))$ recorded during illumination of $\mathrm{B}^{-\mathrm{TiO}_{2}}$ in $0.5 \mathrm{M}$ $\mathrm{K}_{2} \mathrm{SO}_{4}$ electrolyte. b The cyclic voltammetry curves of material electrode recorded in $0.5 \mathrm{M} \mathrm{K}_{2} \mathrm{SO}_{4}$ before and after long-term

thus, measured current under UV-vis illumination could be regarded as a pure photocurrent. In the case of doped material, the significant increase in photocurrent compared to pristine titania nanotubes is observed in the wide potential range from -0.6 up to $+0.9 \mathrm{~V}$ vs. $\mathrm{Ag} / \mathrm{AgCl} / 0.1 \mathrm{M} \mathrm{KCl}$. This increase in resulting from electrode illumination is significantly higher than reported by others $[15,22,61]$, indicating that proposed experimental approach could be regarded as an attractive alternative for other doping methods. The improved photoelectrochemical properties could be assigned to the boron doping which lead to bandgap narrowing, conductivity improvement, and inhibition of charge carrier recombination processes.

In Fig. 10a, b, the transient photocurrent response is given for the pure and the set of boron-doped $\mathrm{TiO}_{2}$ samples prepared under different conditions. The specific parameters of each electrochemical doping procedure (concentration of boric acid, reaction time) are listed in Table 2 together with the photocurrent density registered after $10 \mathrm{~min}$ of measurement duration and enhancement factor (EF). EF is defined as a ratio between photocurrent registered for boron-doped sample and unmodified titania. Such approach used during optimization procedure allows to determine experimental conditions resulting in the most photoactive $\mathrm{B}-\mathrm{TiO}_{2}$ nanotube arrays. Independently from doping conditions (sample: A-119.7, B-199.3. C-123.3, D-199.3, E-310.7, and F$232.8 \mu \mathrm{A} \mathrm{cm}^{-2}$ ), all titania samples doped with boron exhibit much higher photocurrents than non-doped titania $\left(41.7 \mu \mathrm{A} \mathrm{cm}^{-2}\right)$. Furthermore, the lack of steady current diminution suggests that the material is characterized by resistance toward photocorrosion processes. The highest steady-state photocurrent was observed for $\mathrm{B}-\mathrm{TiO}_{2}$ and reached the value of almost $311 \mu \mathrm{A} \mathrm{cm}^{-2}$. The increase of generated photocurrent is influenced by the presence of dopant and can be caused by the decrease of the recombination rate and charge transfer resistance and also enhanced light absorption in the visible

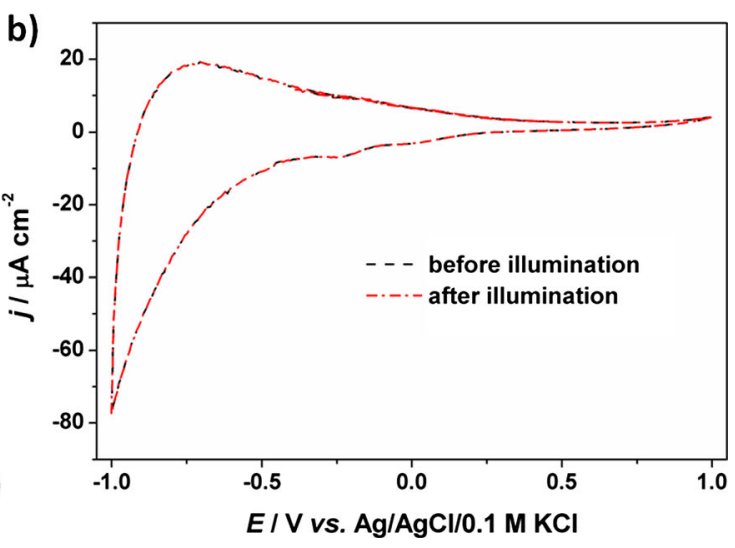

illumination, scan rate $50 \mathrm{mV} \mathrm{s}^{-1}$. The doping conditions are as follows: reaction voltage is $1.8 \mathrm{~V}$, reaction time is $0.5 \mathrm{~h}$, and electrolyte concentration is $0.5 \mathrm{M}$.

range as reported for other types of non-metal-doped nanotube arrays [62]. Summarizing, on the basis of the EF value, the optimal B-doping conditions were determined as follows: reaction time $0.5 \mathrm{~h}$ and electrolyte concentration $0.5 \mathrm{M}$.

As can see in Fig. 11a, even during 120 min of illumination, boron-doped material generates stable photocurrent; thus, obtained material seems to be photocorrosion resistant. Additionally, the $\mathrm{CV}$ curves of $\mathrm{B}-\mathrm{TiO}_{2}$ electrode were recorded in $0.5-\mathrm{M} \mathrm{K}_{2} \mathrm{SO}_{4}$ solution before and after long-term illumination (see Fig. 10b). Therefore, electrochemical measurements also confirm high stability of doped $\mathrm{TiO}_{2}$ nanotube layer in wide potential range.

\section{Conclusions}

In this work, the optimization procedure in order to achieve highly photoactive and stable titania nanotube doped with boron was proposed. It has been found that electrolyte concentration, reaction voltage, and time are the most crucial factors affecting the photoelectrochemical response of the doped material. According to the inspection performed via scanning electron microscopy, the electrochemical doping in electrolyte containing $\mathrm{H}_{3} \mathrm{BO}_{3}$ as boron precursor does not affect the morphology of the as-anodized titania nanotubes. The existence of boron atoms both at the surface and inside the layer confirmed by the energy-dispersive X-ray spectroscopy allows to treat electrochemical doping as efficient technique for boron incorporation. Titania doped by boron atoms possesses lower bandgap energy than pure titania, but the material is still characterized by an anatase crystalline phase. On the basis of the $\mathrm{EF}$, the optimal conditions were determined as follows: reaction time $0.5 \mathrm{~h}$ and boric acid concentration $0.5 \mathrm{M}$. The test performed under sample irradiation showed that $\mathrm{B}$ doping radically improves the photoelectrochemical activity and B$\mathrm{TiO}_{2}$ exhibits 7.5 times higher photocurrent than unmodified 
sample. Summarizing, boron-doped $\mathrm{TiO}_{2}$ NTs could be regarded as a promising photoelectrode material for photovoltaic cells, water splitting, or electrocatalytic processes.

Acknowledgments This work received financial support from the Polish National Science Centre: Grant No. 2012/07/D/ST5/02269. The authors are grateful to K. Karczewski (Gdańsk University of Technology) and K. Grochowska (The Szewalski Institute of Fluid Flow Machinery) for technical support.

Open Access This article is distributed under the terms of the Creative Commons Attribution 4.0 International License (http:// creativecommons.org/licenses/by/4.0/), which permits unrestricted use, distribution, and reproduction in any medium, provided you give appropriate credit to the original author(s) and the source, provide a link to the Creative Commons license, and indicate if changes were made.

\section{References}

1. Balzani V, Credi A, Venturi M (2008) Photochemical conversion of solar energy. ChemSusChem 1:26-58

2. Momeni MM, Ghayeb Y, Mohammadi F (2015) Solar water splitting for hydrogen production with $\mathrm{Fe} 2 \mathrm{O} 3$ nanotubes prepared by anodizing method: effect of anodizing time on performance of Fe2O3 nanotube arrays. J Mater Sci Mater Electron 26:685-692

3. Memming R (2001) Semiconductor Electrochemistry. Weinheim, Wiley-VCH

4. Fujishima A, Rao TN, Tryk DA (2000) Titanium dioxide photocatalysis. J Photochem Photobiol C 1:1-21

5. Carp O, Huisman CL, Reller A (2004) Photoinduced reactivity of titanium dioxide. Prog Solid State Chem 32:33-177

6. Zhong P, Liao Y, Que W, Jia Q, Lei T (2014) Enhanced electron collection in photoanode based on ultrafine $\mathrm{TiO} 2$ nanotubes by a rapid anodization process. J Solid State Electrochem 18:2087-2098

7. Beranek R, Macak JM, Gärtner M, Meyer K, Schmuki P (2009) Enhanced visible light photocurrent generation at surface-modified TiO2 nanotubes. Electrochim Acta 54:2640-2646

8. Momeni MM, Ghayeb Y (2015) Visible light-driven photoelectrochemical water splitting on $\mathrm{ZnO}-\mathrm{TiO} 2$ heterogeneous nanotube photoanodes. J Solid State Electrochem 45:557-566

9. Momeni MM, Ghayeb Y (2015) Fabrication, characterization and photoelectrochemical behavior of $\mathrm{Fe}-\mathrm{TiO} 2$ nanotubes composite photoanodes for solar water splitting. J Solid State Electrochem 751:43-48

10. Gong J, Pu W, Yang C, Zhang J (2013) Novel one-step preparation of tungsten loaded $\mathrm{TiO} 2$ nanotube arrays with enhanced photoelectrocatalytic activity for pollutant degradation and hydrogen production. Catal Commun 36:89-93

11. Momeni MM, Ghayeb Y, Ghonchegi Z (2015) Fabrication and characterization of copper doped $\mathrm{TiO} 2$ nanotube arrays by in situ electrochemical method as efficient visible-light photocatalyst. Ceram Int 41:8735-8741

12. Momeni MM, Ghayeb Y (2015) Photoelectrochemical water splitting on chromium-doped titanium dioxide nanotube photoanodes prepared by single-step anodizing. J Alloys Compd 637:393-400

13. Siuzdak K, Szkoda M, Sawczak M, Lisowska-Oleksiak A (2015) Novel nitrogen precursors for electrochemically driven doping of titania nanotubes exhibiting enhanced photoactivity. New J Chem 39:2741-2751

14. Siuzdak K, Szkoda M, Sawczak M, Lisowska-Oleksiak A, Karczewski J, Ryl J (2015) Enhanced photoelectrochemical and photocatalytic performance of iodine-doped titania nanotube arrays. RSC Adv 5:50379-50391

15. Lu N, Zhao H, Li J, Quan X, Chen S (2008) Characterization of boron-doped $\mathrm{TiO} 2$ nanotube arrays prepared by electrochemical method and its visible light activity. Sep Purif Technol 62:668-673

16. Momeni MM, Ghayeb Y, Ghonchegi Z (2015) Visible light activity of sulfur-doped $\mathrm{TiO} 2$ nanostructure photoelectrodes prepared by single-step electrochemical anodizing process. J Solid State Electrochem 19:1359-1366

17. Spanggaard H, Krebs FC (2004) A brief history of the development of organic and polymeric photovoltaics. Sol Energy Mater Sol Cells 83:125-146

18. Shankar K, Mor GK, Prakasam HE, Varghese OK, Grimes CA (2007) Self-assembled hybrid polymer-TiO2 nanotube array heterojunction solar cells. Langmuir 23:12445-12449

19. Lu N, Quan X, Li JY, Chen S, Yu HT, Chen GH (2007) Fabrication of boron-doped $\mathrm{TiO} 2$ nanotube array electrode and investigation of its photoelectrochemical capability. J Phys Chem C 111:1183611842

20. Lisowska-Oleksiak A, Szybowska K, Jasulaitienè V (2010) Preparation and characterisation of visible light responsive iodine doped TiO2 electrodes. Electrochim Acta 55:5881-5885

21. Chen D, Yang D, Wang Q, Jiang Z (2006) Effects of boron doping on photocatalytic activity and microstructure of titanium dioxide nanoparticles. Ind Eng Chem Res 45:4110-4116

22. Li J, Lu N, Quan X, Chen S, Zhao H (2008) Facile method for fabricating boron-doped $\mathrm{TiO} 2$ nanotube array with enhanced photoelectrocatalytic properties. Ind Eng Chem Res 47:3804-3808

23. Subramanian A, Wang HW (2012) Effects of boron doping in $\mathrm{TiO} 2$ nanotubes and the performance of dye-sensitized solar cells. Appl Surf Sci 258:6479-6484

24. Zhao W, Ma WH, Chen CC, Zhao JC, Shuai ZG (2004) Efficient degradation of toxic organic pollutants with Ni2O3/TiO2-xBx under visible irradiation. J Am Chem Soc 126:4782-4783

25. In S, Orlov A, Berg R, Garcia F, Pedrosa-Jimenez S, Tikhov MS, Wright DS, Lambert RM (2007) Effective visible light-activated Bdoped and B N-codoped TiO2 photocatalysts. J Am Chem Soc 129: 13790-13791

26. Bettinelli M, Dallacasa V, Falcomer D, Fornasiero P, Gombac V, Montini T, Roman'o L, Speghini A (2007) Photocatalytic activity of TiO2 doped with boron and vanadium. J Hazard Mater 146:529534

27. Finazzi E, Valentin CD, Pacchioni G (2009) Boron-doped anatase TiO2: pure and hybrid DFT calculations. J Phys Chem C 113:220 228

28. Momeni MM, Ghayeb Y, Davarzadeh M (2015) Single-step electrochemical anodization for synthesis of hierarchical WO3-TiO2 nanotube arrays on titanium foil as a good photoanode for water splitting with visible light. J Electroanal Chem 739:149-155

29. Szkoda M, Siuzdak K, Lisowska-Oleksiak A (2015) Optimization of electrochemical doping approach resulting in highly photoactive iodine-doped titania nanotubes. J Solid State Electrochem. doi:10. 1007/s10008-015-3081-7

30. Pu P, Cachet H, Ngaboyamahina E, Sutter EMM (2013) Relation between morphology and conductivity in $\mathrm{TiO} 2$ nanotube arrays: an electrochemical impedance spectrometric investigation. J Solid State Electrochem 17:817-828

31. Bessegato GG, Cardoso JC, Zanoni MVB (2015) Enhanced photoelectrocatalytic degradation of an acid dye with borondoped $\mathrm{TiO} 2$ nanotube anodes. Catal Today 240:100-106

32. Zhuang H, Lin C, Lai Y, Sun L, Li J (2007) Some critical structure factors of titanium oxide nanotube array in its photocatalytic activity. Environ Sci Technol 41:4735-4740

33. Deng L, Chen Y, Yao M, Wang S, Zhu B, Huang W, Zhang S (2010) Synthesis, characterization of B-doped $\mathrm{TiO} 2$ nanotubes with high photocatalytic activity. J Sol-Gel Sci Technol 53:535-541 
34. Dozzi MV, Selli E (2013) Doping TiO2 with p-block elements: effects on photocatalytic activity. J Photochem Photobiol C: Photochem Rev 14:13-28

35. Shannon RD (1976) Revised effective ionic radii and systematic studies of interatomic distances in halides and chalcogenides. Acta Cryst A 32:751-767

36. Yu JG, Dai GP, Cheng B (2010) Effect of crystallization methods on morphology and photocatalytic activity of anodized $\mathrm{TiO} 2$ nanotube array films. J Phys Chem C 114:19378-19385

37. Cheng X, Liu H, Chen Q, Li J, Wang P (2013) Construction of N, S codoped $\mathrm{TiO} 2 \mathrm{NCs}$ decorated $\mathrm{TiO} 2$ nano-tube array photoelectrode and its enhanced visible light photocatalytic mechanism. Electrochim Acta 103:134-142

38. Jeong JH, Jung DW, Shin EW, Oh ES (2014) Boron-doped TiO2 anode materials for high-rate lithium ion batteries. J Alloys Compd 604:226-232

39. Yu JG, Yu HG, Cheng B, Zhao WJ, Yu JC, Ho WK (2003) The effect of calcination temperature on the surface microstructure and photocatalytic activity of $\mathrm{TiO} 2$ thin films prepared by liquid phase deposition. J Phys Chem B 107:13871-13879

40. Nam SH, Cho SJ, Boo JH (2012) Growth behavior of titanium dioxide thin films at different precursor temperatures. Nanoscale Res Lett 7:1-6

41. Kamal MSK, Mohamed IZJ (1997) Synthesis of high surface area titania powders via basic hydrolysis of titanium (IV) isopropoxide. Powder Technol 92:233-239

42. Szkoda M, Siuzdak K, Lisowska-Oleksiak A, Karczewski J, Ryl J (2015) Facile preparation of extremely photoactive boron-doped $\mathrm{TiO} 2$ nanotube arrays. Electrochem Commun 60:212-215

43. Wei C, Rang X, Liang J, Tan S (2007) Growth behavior of titanium dioxide thin films at different precursor temperatures. J Environ Sci 19:90-96

44. Li L, Yang Y, Liu X, Fam R, Shi Y, Li S, Zhang L, Fan X, Tang P, Xu R, Zhang W, Wang Y, Ma L (2013) Growth behavior of titanium dioxide thin films at different precursor temperatures. Appl Surf Sci 265:36-40

45. Raghunath P, Lin MC (2008) Adsorption configurations and reactions of boric acid on a TiO2 anatase (101) surface. J Phys Chem C 112:8276-8287

46. Feng N, Zheng A, Wang Q, Ren P, Gao X, Liu SB, Shen Z, Chen T, Deng F (2011) Boron environments in B-doped and (B, N)codoped TiO2 photocatalysts: a combined solid-state NMR and theoretical calculation study. J Phys Chem C 115:2709-2719

47. Siuzdak K, Szkoda M, Lisowska-Oleksiak A, Grochowska K, Karczewski J, Ryl J (2015) Thin layer of ordered boron-doped $\mathrm{TiO} 2$ nanotubes fabricated in a novel type of electrolyte and characterized by remarkably improved photoactivity. Appl Surf Sci 357:942-950

48. Fross L, Schubnell M (1993) Temperature dependence of the luminescence of TiO2 powder. Appl Phys B: Photophys Laser Chem 56: $363-366$
49. Jung KY, Park SB, Matsuoka M, Anpo M (2003) In-situ investigations of the photoluminescence properties of $\mathrm{SiO} 2 / \mathrm{TiO} 2$ binary and Boron-SiO2/TiO2 ternary oxides prepared by the sol-gel method and their photocatalytic reactivity for the oxidative decomposition of trichloroethylene. Int J Photogr 5:31-36

50. Begum NS, Ahmed HMF, Hussain OM (2008) Characterization and photocatalytic activity of boron-doped $\mathrm{TiO} 2$ thin films prepared by liquid phase deposition technique. Bull Mater Sci 31: 741-745

51. Li H, Xing J, Xia Z, Chen J (2014) Preparation of extremely smooth and boron-fluorine co-doped $\mathrm{TiO} 2$ nanotube arrays with enhanced photoelectrochemical and photocatalytic performance. Electrochim Acta 139:331-336

52. Kim S, Yoo H, Rhee O, Choi J (2015) Doping of Pt into anodic $\mathrm{TiO} 2$ nanotubes for Water Oxidation: Underpotential shock method in Cl- solution. J Phys Chem C 119:21497-21503

53. Munoz AG, Chen Q, Schmuki P (2007) Interfacial properties of self-organized $\mathrm{TiO} 2$ nanotubes studied by impedance spectroscopy. J Solid State Electrochem 11:1077-1084

54. Bonham DB, Orazem ME (1992) a mathematical model for the influence of deep-level electronic states on photoelectrochemical impedance spectroscopy II. Assessment of characterization methods based on mott-schottky theory. J Electrochem Soc 139: $127-131$

55. Wang Z, Zhao J, Wang X, Zhou J (2015) Causes for the Formation of Titania Nanotubes During Anodization. IEEE Trans Nanotechnol 14:113-117

56. Gelderman K, Lee DSW (2007) Flat-band potential of semiconductor: using the Mott-Schottky equation. J Chem Educ 84:685-689

57. Gu F, Huang W, Wang S, Cheng X, Hu Y, Lee PS (2014) Opencircuit voltage improvements in tantalum-doped $\mathrm{TiO} 2$ nanocrystals. Phys Chem Chem Phys 16:25679-25683

58. Macyk W, Burgeth G, Kisch H (2003) Photoelectrochemical properties of platinum (IV) chloride surface modified TiO2. Potochem Photobiol Sci 2:322-328

59. Tang H, Prasad K, Sanjines R P, Levy F (1994) Electrical and optical properties of $\mathrm{TiO} 2$ anatase thin films. J Appl Phys 75: 2042-2047

60. Chen B, Beach JA, Maurya D, Moore RB, Priya S (2014) Fabrication of black hierarchical $\mathrm{TiO} 2$ nanostructures with enhanced photocatalytic activity. RSC Adv 4:29443-29449

61. Cui H, Zhao W, Yang C, Yin H, Lin T, Shan Y, Xie Y, Gu H, Hang F (2014) Black TiO2 nanotube arrays or high-efficiency photoelectrochemical water-splitting. J Mater Chem A 2:86128616

62. Lu X, Ang GW, Zhai T, Yu M, Gan J, Tong Y, Li Y (2012) Hydrogenated $\mathrm{TiO} 2$ nanotube arrays for supercapacitors. Nano Lett 12:1690-1696 